\title{
Landscape-scale temporal stability of soil water storage within profiles on the semiarid Loess Plateau of China
}

\author{
Xuezhang Li $\cdot$ Mingan Shao $\cdot$ Xiaoxu Jia $\cdot$ Xiaorong Wei
}

Received: 2 November 2014 / Accepted: 2 January 2015 /Published online: 27 January 2015

(C) Springer-Verlag Berlin Heidelberg 2015

\begin{abstract}
Purpose Knowledge of the temporal stability of soil water storage (SWS) at landscape scale is scarce. The recognition of landscape-scale temporal evolution of soil water profiles is critical for soil water management and vegetational restoration in semiarid watersheds.

Materials and methods Soil moisture was measured with neutron probes to a depth of $3.0 \mathrm{~m}$ on 18 sampling dates at 135 locations along a landscape transect from August 2012 to October 2013. Temporal stability of SWS at a landscape scale and a point scale was examined using Spearman's rank correlation analysis and indices of standard deviation of relative difference and mean absolute bias error, respectively.

Results and discussion The mean spatial SWS in the shallow soil layer $(0-1.0 \mathrm{~m})$ was relatively more variable temporally than in the deeper soil layers (1.0-3.0 m), and the mean SWS in the deep soil layer $(2.0-3.0 \mathrm{~m})$ was more variable spatially. The mean Spearman's rank correlation coefficient increased with increasing soil depth and decreased with increasing time lags between measurements for the deeper soil layers (1.0 $3.0 \mathrm{~m}$ ). The number of temporally stable locations and the accuracy of prediction for predicting the mean SWS increased with increasing soil depth. The temporal stability of the SWS patterns was controlled by soil texture, organic carbon
\end{abstract}

Responsible editor: Fanghua Hao

X. Li $\cdot$ M. Shao $(\bowtie) \cdot$ X. Jia

Key Laboratory of Ecosystem Network Observation and Modeling, Institute of Geographic Sciences and Natural Resources Research,

Chinese Academy of Sciences, Beijing 100101, China

e-mail: shaoma@igsnrr.ac.cn

X. Li

University of Chinese Academy of Sciences, Beijing 100049, China

$X$. Wei

State Key Laboratory of Soil Erosion and Dryland Farming on the Loess Plateau, Northwest A\&F University, Yangling 712100, China content, bulk density, and saturated soil hydraulic conductivity. Aboveground biomass and site elevation (except for the 2.0-3.0-m layer), however, affected the temporal persistence of SWS relatively weakly.

Conclusions This study provides useful information for estimating mean SWS at the landscape scale and may improve the management of soil water on the semiarid Loess Plateau of China.

Keywords Landscape scale $\cdot$ Representative location $\cdot$ Soil water storage $\cdot$ Temporal persistence $\cdot$ The Loess Plateau

\section{Introduction}

Soil water storage (SWS) plays an important role in many hydrological and ecological processes, such as surface runoff, infiltration, water and energy fluxes, and plant transpiration (Martínez-Fernández and Ceballos 2003; Brocca et al. 2009; Heathman et al. 2012). Soil water storage is also a crucial factor in semiarid ecosystems for vegetational restoration and water management ( $\mathrm{Hu}$ et al. 2010b; Jia et al. 2013a). Knowledge of the behavior of SWS and its spatiotemporal distribution thus provides fundamental information for hydrological modeling and prediction, restoration of vegetation, and sustainability of land use.

Soil water content is highly variable over time and space due to the heterogeneity of controlling factors and their combinations, leading to challenges for estimating water status. Repeated surveys of soil water content at fixed locations in a field, however, can identify locations where soil moisture is consistently higher than, equal to, or lower than the average field soil water content (Pachepsky et al. 2005; Zhou et al. 2007; Guber et al. 2008). Vachaud et al. (1985) first termed this phenomenon as temporal stability, which described a persistent 
spatial pattern of soil water content between measurement occasions. The temporal stability technique can provide missing data of soil water content (Dumedah and Coulibaly 2011) and can reduce time, labor costs, and disturbance of the soil structure. The most important application of temporal stability is to estimate mean soil water content of an entire study area of interest using representative locations. The utility of this application has been demonstrated by many researchers (GómezPlaza et al. 2000; Grayson et al. 2002; Starks et al. 2006; Brocca et al. 2012; Jia et al. 2013a; Hu and Si 2014).

Most studies on the temporal stability of soil water content in various areas have focused on the surface soil layer (Famiglietti et al. 1998; Cosh et al. 2008; Schneider et al. 2008; Zhao et al. 2010; Wang et al. 2013; Zhang and Shao 2013) or within 1.0-m profile (Hupet and Vanclooster 2002; Starks et al. 2006; Guber et al. 2008; Hu et al. 2010b; Gao et al. 2011), and only few have addressed deeper soil profiles. Hydrological processes may differ among surface and subsurface soil layers, so understanding the dependence of the temporal stability of soil water content in depth is necessary. Most studies have also focused mainly on the dynamics of soil moisture during the growing season (Hu et al. 2010a, 2010b; Gao and Shao 2012a, 2012b; Jia et al. 2013a, 2013b), and the effect of snowfall in winter on SWS has been neglected. Maule et al. 1994, however, studied the contribution of winter precipitation to the recharge of soil water and/or groundwater in a prairie agricultural site using stable isotope method and showed that $27 \%$ of soil water and $44 \%$ of groundwater came from snow water, suggesting that the contribution of winter rainfall to soil water cannot be ignored. Biswas and $\mathrm{Si}$ (2011a) observed a stronger similarity in the large-scale (>72 m) spatial patterns of soil water between the surface and deeper layers during the recharge period than during the discharge period. Data for soil moisture outside the growing season should thus be considered in the analysis of SWS temporal stability. Furthermore, the concept of temporal stability has been applied at plot (Pachepsky et al. 2005; Jia and Shao 2013), slope (Jia et al. 2013a), watershed (Hu et al. 2010b), and regional scales (Martínez-Fernández and Ceballos 2003). The temporal stability of SWS at landscape scales and with various types of vegetation, landforms, and soils, however, has not received much attention. Information on the temporal stability of SWS at the landscape scale may be helpful for scale transformation, especially for the upscaling process.

Many factors can affect the temporal stability of the spatial patterns of SWS, such as soil properties, topography, and vegetation. Elucidating the influence of these factors is useful both for identifying representative locations and for projecting temporally stable locations that have not yet been sampled (Vanderlinden et al. 2012). Soil texture has been the dominant factor affecting temporal stability in watersheds $(\mathrm{Hu}$ et al. 2010b; Vachaud et al. 1985; Zhao et al. 2010). Mohanty and Skaggs (2001) indicated that sandy loam soils were more temporally stable than silty loam soils because the silt loam soil was more variable in terms of space-time dynamics of soil moisture processes as compared to the sandy loam soil. Jacobs et al. 2004, though, reported that the more temporally stable locations were associated with moderate to moderately high (28-30\%) clay contents. Representative locations for the mean soil water content should also be locations that capture the average topographic characteristics (Grayson and Western 1998; Vivoni et al. 2008), and vegetational cover can affect the temporal stability of soil moisture (Schneider et al. 2008; Jia and Shao 2013). The effects of these factors on temporal stability are scale dependent (Kachanoski and de Jong 1988; Biswas and Si 2011b). The objective of this study was to investigate the temporal stability of SWS profiles at a landscape scale on the semiarid Loess Plateau of China. Specific concerns were (1) the spatial pattern of SWS with increasing soil depth, (2) the effects of the factors controlling the temporal stability of SWS at a landscape scale, and (3) the identification of representative locations for estimating the mean SWS of this area of interest.

\section{Materials and methods}

\subsection{Study area and experimental design}

This study was conducted along a typical transect of a catchment (Liudaogou catchment) on the Loess Plateau $\left(110^{\circ} 21^{\prime}\right.$ to $110^{\circ} 23^{\prime}$ E, $38^{\circ} 46^{\prime}$ to $38^{\circ} 51^{\prime} \mathrm{N}$ ), Shenmu County, Shaanxi Province, China (Fig. 1). This area belongs to the water-wind erosion crisscross region with crucial environmental conditions. The Liudaogou catchment is characterized by undulating loessial slopes and deep gullies. The mean annual temperature is $8.4{ }^{\circ} \mathrm{C}$, and the mean annual precipitation is $437 \mathrm{~mm}$, approximately $70 \%$ of which falls from June to September (Fig. 2). The elevation of the Liudaogou catchment ranges from 1056 to $1130 \mathrm{~m}$. The primary soils are aeolian sandy soils and UstSandic Entisol soils. The dominant vegetation includes purple alfalfa (Medicago sativa L.), Korshinsk Peashrub (Caragana korshinskii K.), and bunge needlegrass (Stipa bungeana T.).

A landscape-scale transect $1340 \mathrm{~m}$ in length with 135 measuring locations was established in an east-west direction across several sub-catchments (Fig. 1c). The locations were $10 \mathrm{~m}$ apart, with a few exceptions due to gullies. An aluminum neutron probe access tube $3.3 \mathrm{~m}$ in length was installed at each location for the measurement of soil water content.

\subsection{Data collection}

\subsubsection{Measurement of SWS}

The SWS at three depths $(0-1.0,1.0-2.0$, and 2.0-3.0 m) were measured with neutron probes at 135 locations along a 

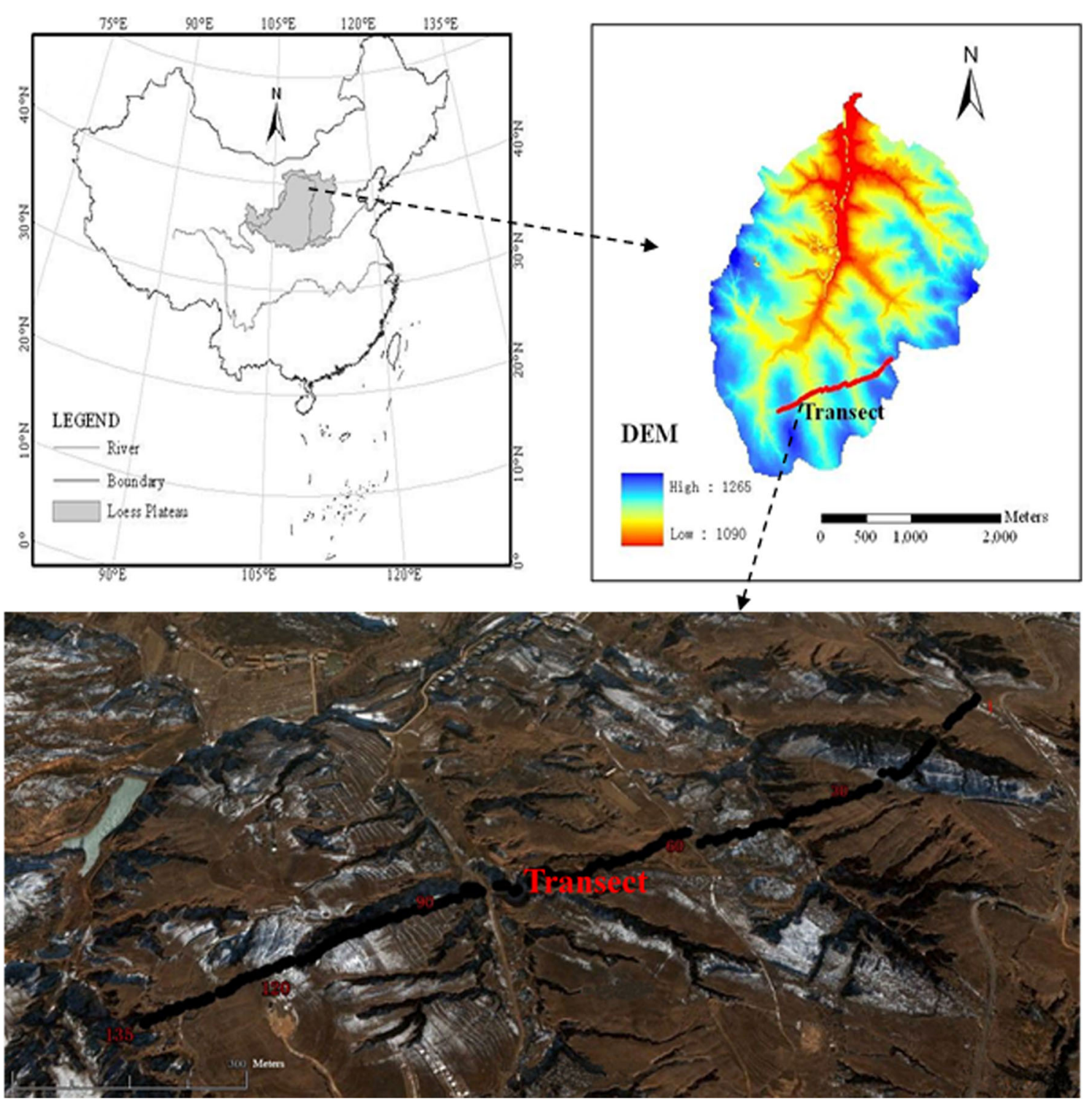

Fig. 1 Location of the study area and transect position in the Liudaogou catchment

landscape-scale transect on 18 sampling dates in 2012 and 2013. Slow neutron counting rates were obtained at intervals of $20 \mathrm{~cm}$ from a depth of $0.2-3.0 \mathrm{~m}$ from 23 August 2012 to
28 October 2013. Twelve locations were selected along the transect to establish calibration curves. The mean and the range of the neutron counting data for the 12 tubes
Fig. 2 Distribution of daily rainfall and mean air temperature in the study area in 2012-2013

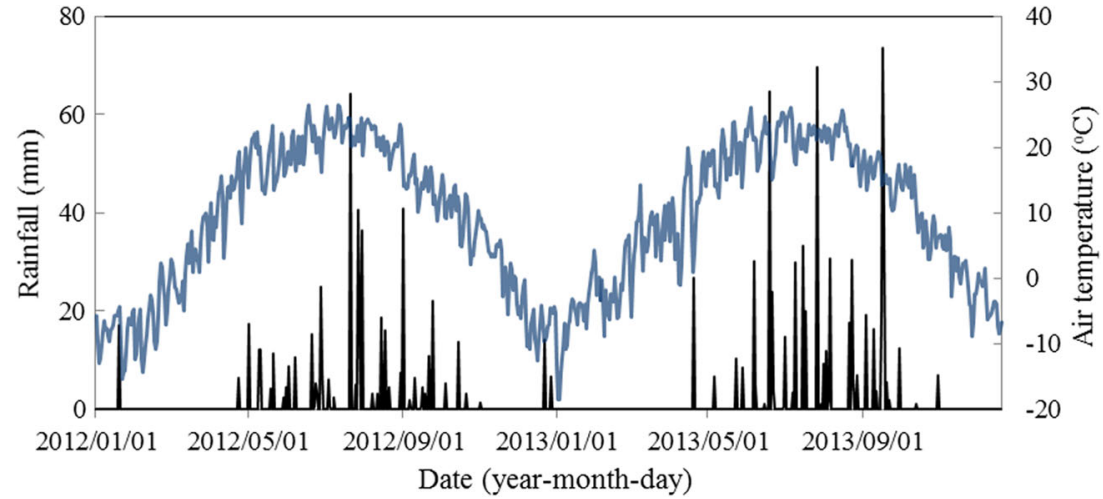


approximated those of all tubes (Hu et al. 2010b). Gravimetric soil water content at these 12 locations was determined at ten depths about $0.5 \mathrm{~m}$ from each tube. A pit $1.0 \mathrm{~m}$ deep was excavated at each location to obtain undisturbed soil samples for the determination of bulk density and for the transformation of gravimetric soil water contents into corresponding volumetric soil water contents. Volumetric soil water content at each soil depth could then be calculated using the following calibration equation:

$\theta=65.647 C R-0.6779\left(R^{2}=0.9031, \quad P<0.001\right)$

where $C R$ is the slow neutron counting rate.

The SWSs of the $0-1.0-, 1.0-2.0-$, and $2.0-3.0-\mathrm{m}$ soil layers were calculated by the following equations:

$$
S W S_{i j(0-1.0 m)}=200 \times\left[\theta_{i j(200)}+\theta_{i j(400)}+\theta_{i j(600)}+\theta_{i j(800)}+\theta_{i j(1000)}\right]
$$

$$
\begin{aligned}
S W S_{i j(1.0-2.0 m)}= & 200 \\
& \times\left[\theta_{i j(1200)}+\theta_{i j(1400)}+\theta_{i j(1600)}+\theta_{i j(1800)}+\theta_{i j(2000)}\right]
\end{aligned}
$$

$$
\begin{aligned}
S W S_{i j(2.0-3.0 m)}= & 200 \\
& \times\left[\theta_{i j(2200)}+\theta_{i j(2400)}+\theta_{i j(2600)}+\theta_{i j(2800)}+\theta_{i j(3000)}\right]
\end{aligned}
$$

where $i$ is the location, $j$ is the sampling occasion, and the numbers in the subscript refer to different soil depths (mm).

\subsubsection{Measurement of other main characteristics}

An RTK-GPS receiver with a resolution of $5 \mathrm{~m}$ was used to determine the sampling locations and associated elevations. A cutting ring (5-cm length; $20-\mathrm{cm}^{2}$ cross section) was used to obtain undisturbed soil samples at each location $0.2 \mathrm{~m}$ from the aluminum tube for measurements of soil bulk density and of saturated soil hydraulic conductivity $(K s)$ using the constant-head method (Klute and Dirksen 1986). Disturbed soil samples collected during installation of the aluminum tubes were divided into two sub-samples and were air-dried. The two sub-samples were then passed through a 1-mm sieve and a $0.25-\mathrm{mm}$ sieve for laboratory analysis. Soil particle sizes were evaluated using a Mastersizer2000 (Malvern instruments, Malvern, UK). Soil organic carbon (OC) content was determined by the dichromate oxidation method (Nelson and Sommers 1982). The maximum amount of biomass was collected from an area of $1 \times 1 \mathrm{~m}$ at each location in September 2013 and was oven-dried at $75{ }^{\circ} \mathrm{C}$ for $72 \mathrm{~h}$ to obtain the dry weight. The properties of the soil $(0-20 \mathrm{~cm})$, topography, and vegetation for the transect are summarized in Table 1.
Table 1 Classical statistics for selected soil $(0-20 \mathrm{~cm})$ properties (bulk density, BD; saturated soil hydraulic conductivity, Ks; clay content, Clay; silt content, Silt; sand content, Sand; and organic-carbon content, OC), site elevation (SE), and aboveground biomass (AGB) of 135 locations along the transect

\begin{tabular}{llllll}
\hline Variables & Max & Min & Mean & SD & CV \% \\
\hline BD $\left(\mathrm{g} \mathrm{cm}^{-3}\right)$ & 1.7 & 1.2 & 1.4 & 0.1 & 9.0 \\
Ks $\left(\mathrm{mm} \mathrm{min}^{-1}\right)$ & 3.7 & 0.0 & 0.8 & 0.7 & 88.0 \\
Clay $(\%)$ & 23.6 & 0.0 & 11.1 & 5.6 & 51.0 \\
Silt $(\%)$ & 73.0 & 0.0 & 44.6 & 19.4 & 43.0 \\
Sand $(\%)$ & 100.0 & 4.1 & 44.3 & 24.5 & 55.0 \\
OC $\left(\mathrm{g} \mathrm{kg}^{-1}\right)$ & 10.7 & 0.5 & 3.7 & 1.8 & 48.0 \\
SE $(\mathrm{m})$ & 1259.0 & 1180.0 & 1218.1 & 19.8 & 2.0 \\
AGB $\left(\mathrm{g} \mathrm{m}^{-2}\right)$ & 627.8 & 5.0 & 226.0 & 125.1 & 55.0 \\
\hline
\end{tabular}

\subsection{Assessment of the temporal stability of SWS}

The nonparametric Spearman's correlation test was used to evaluate the overall spatial pattern of temporal stability (Vachaud et al. 1985). The Spearman's rank correlation coefficient, $r_{s}$, is defined by:

$r_{s}=1-\frac{6 \sum_{i=1}^{N}\left(R_{i j}-R_{i j^{\prime}}\right)^{2}}{N\left(N^{2}-1\right)}$

where $R_{i j}$ is the rank of the variable at location $i$ for measurement occasion $j, R_{i j}$, is the rank of the same variable at the same location but for measurement occasion $j^{\prime}$, and $N$ is the number of observations. An $r_{s}$ equal to unity between sampling dates indicates complete temporal persistence of the spatial pattern.

The relative difference of SWS for each sampling location $i$ at depth $k$ for measurement time $j$ is calculated as

$\delta_{i j k}=\frac{S W S_{i j k}-\overline{S W S_{j k}}}{\overline{S W S_{j k}}}$

where $\overline{\mathrm{SWS}}_{j k}$ is the mean SWS at depth $k$ for all 135 sampling locations at time $j$ :

$\overline{S W S_{j k}}=\frac{1}{M} \sum_{i=1}^{M} S W S_{i j k}$

where $M$ is the number of sampling locations of the transect. 
The temporal mean relative difference (MRD), $\overline{\delta_{i k}}$, and the standard deviation of relative difference (SDRD) over time, $\sigma\left(\delta_{i k}\right)$, are expressed as

$$
\overline{\delta_{i k}}=\frac{1}{N} \sum_{j=1}^{N} \delta_{i j k}
$$

$$
\sigma\left(\delta_{i k}\right)=\sqrt{\frac{1}{N-1} \sum_{j=1}^{N}\left(\delta_{i j k}-\overline{\delta_{i k}}\right)^{2}}
$$

where $N$ is the total number of sampling occasions. Locations with MRDs close to zero can accurately estimate mean SWS, but locations with MRDs higher or lower than zero will overestimate or underestimate SWS, respectively. The SDRD can identify temporally stable locations; a lower value of SDRD corresponds to a more temporally stable location. The index of temporal stability (ITS) was introduced using a combination of MRD and the associated SDRD as (Jacobs et al. 2004; Zhao et al. 2010)

$$
I T S_{i k}=\sqrt{{\overline{\delta_{i k}}}^{2}+\sigma\left(\delta_{i k}\right)^{2}}
$$

The ITS provides a single metric for identifying the sampling locations that are closest to the mean SWS and that are also temporally stable. The most temporally stable location notably has the lowest ITS. The ITS can also be used to identify representative location for directly estimating the mean SWS (Hu et al. 2012). In this study, locations with an ITS under $10 \%$ are selected to be representative points (Jia et al. 2013a). Another index is the mean absolute bias error (MABE), introduced by $\mathrm{Hu}$ et al. (2010a), which characterizes temporal stability. Following Eq. (6), the mean SWS at depth $k$ at measurement occasion $j$ can be calculated as

$\overline{S W S_{j k}}=\frac{S W S_{i j k}}{1+\delta_{i j k}}$

Assuming a constant offset, $\overline{\delta_{i k}}$, for a temporally stable location (Grayson and Western 1998), the estimated, $\overline{\mathrm{SWS}}_{j k}$, $\overline{\mathrm{SWS}}_{j k}$ can be expressed as

$$
\overline{S W S_{j k}}=\frac{S W S_{i j k}}{1+\overline{\delta_{i k}}}
$$

The bias error of the mean SWS, $\varphi_{i j k}$, can thus be written as

$\varphi_{i j k}=\frac{\overline{S W S_{j k}}-\overline{S W S_{j k}}}{\overline{S W S_{j k}}}$

Substituting Eqs. (11) and (12) into Eq. (13), then

$\varphi_{j k}=\frac{\delta_{i j k}-\overline{\delta_{i k}}}{1+\overline{\delta_{i k}}}$

The mean absolute bias error, $\mathrm{MABE}_{i k}$, can thus be defined as

$M A B E_{i k}=\frac{1}{N} \sum_{j=1}^{N}\left|\frac{\delta_{i j k}-\overline{\delta_{i k}}}{1+\overline{\delta_{i k}}}\right|$

where $N$ is the total number of sampling occasions. MABE, hence, directly describes the time-averaged bias error for the $i$ th location to produce the mean SWS at depth $k$ when persistently assuming an offset of $\overline{\delta_{i k}}$. A lower MABE indicates less bias error and more temporally stable locations.

The root-mean-square error (RMSE) of the predicted mean SWS after applying the offset is calculated as

$R M S E=\sqrt{\frac{1}{N} \sum_{i=1}^{N}\left(P_{i}-p_{i}\right)^{2}}$

where $P_{i}$ and $p_{i}$ are the predicted and measured values, respectively.

\subsection{Statistical analysis}

Pearson correlation analysis was used to analyze the relationships between the temporal stability of the SWS profiles and the properties of the soil, topography, and vegetation. Linear fitting analysis was carried out between the observed and estimated mean SWSs, with the root-mean-square error (RMSE) as a measure of the goodness of fit. Independent samples $t$ tests were performed to test for differences in SWS among the soil depths. The statistical analyses of the SWS data used SPSS 16.0 software. 


\section{Results and discussion}

3.1 Spatiotemporal dynamics of SWS for the various soil layers

Figure 3a presents the temporal evolution of the mean spatial SWS for the different soil layers. The time-averaged mean spatial SWSs for the entire transect were 149.8, 138.6, and $143.5 \mathrm{~mm}$ for the $0-1.0-, 1.0-2.0-$, and $2.0-3.0-\mathrm{m}$ soil layers, with ranges of $87.5,43.5$, and $22.6 \mathrm{~mm}$, respectively. The SWSs for the various soil layers were not significant at $P<0.05$ (Table 2). The mean spatial SWSs from 16 December 2012 to 18 March 2013 were relatively stable for each layer, indicating weak soil water dynamics during this period (Fig. 3a). The mean spatial SWS for the $0-1.0-\mathrm{m}$ layer, however, dramatically decreased from 16 April 2013 to 15 June 2013 (Fig. 3a), which can be attributed to the consumption of water by the plants in this layer (Jia et al. 2013a) and/or to low precipitation (Fig. 2). The mean SWS for this layer gradually increased and then fluctuated around a high value (Fig. 3a), likely due to the relatively higher amounts of subsequent precipitation (Fig. 2). The mean spatial SWS was less
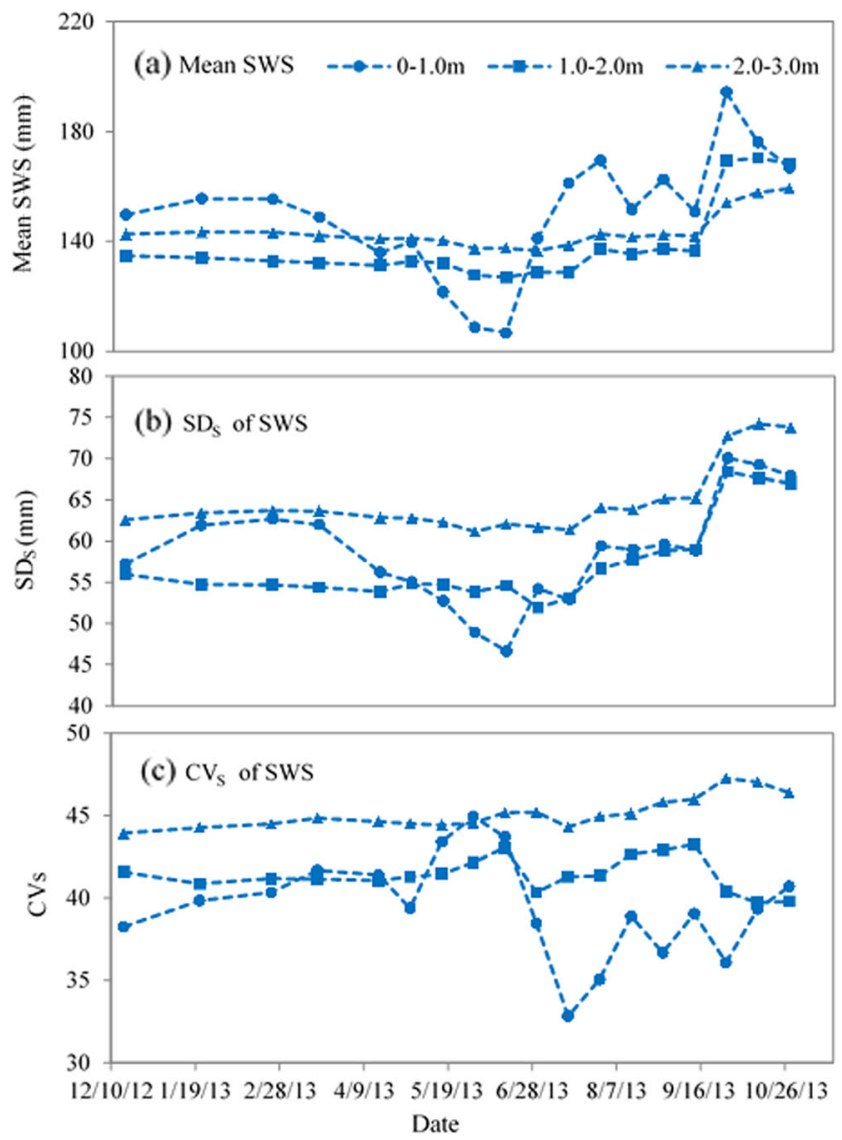

Fig. 3 Spatial mean soil water storage (SWS) and the corresponding standard deviation $\left(S D_{S}\right)$ and coefficient variation $\left(C V_{S}\right)$ for the various soil layers
Table 2 Temporal statistics for spatial soil water storage (SWS) and the associated standard deviation $\left(\mathrm{SD}_{\mathrm{S}}\right)$ and coefficient of variation $\left(\mathrm{CV}_{\mathrm{S}}\right)$ for the various soil layers

\begin{tabular}{lllll}
\hline Spatial variables & Temporal statistics & $0-1.0 \mathrm{~m}$ & $1.0-2.0 \mathrm{~m}$ & $2.0-3.0 \mathrm{~m}$ \\
\hline Mean SWS & Mean (mm) & $149.8 * \mathrm{a}$ & $138.6 \mathrm{a}$ & $143.5 \mathrm{a}$ \\
& Max (mm) & 194.2 & 170.4 & 159.2 \\
& Min (mm) & 106.7 & 126.8 & 136.5 \\
& $\mathrm{SD}_{\mathrm{T}}(\mathrm{mm})$ & 22.2 & 14.5 & 6.6 \\
$\mathrm{SD}_{\mathrm{S}}$ of SWS & $\mathrm{CV}_{\mathrm{T}}(\%)$ & 14.9 & 10.4 & 4.6 \\
& Mean (mm) & $58.6 \mathrm{a}$ & $57.3 \mathrm{a}$ & $64.8 \mathrm{~b}$ \\
& Max (mm) & 70.1 & 68.4 & 74.2 \\
& Min (mm) & 46.6 & 51.9 & 61.2 \\
& $\mathrm{SD}_{\mathrm{T}}(\mathrm{mm})$ & 6.5 & 5.1 & 4.2 \\
$\mathrm{CV}_{\mathrm{S}}$ of SWS & $\mathrm{CV}(\%)$ & 11.1 & 8.9 & 6.5 \\
& $\mathrm{Mean}_{\mathrm{T}}(\mathrm{mm})$ & $39.4 \mathrm{a}$ & $41.4 \mathrm{~b}$ & $45.2 \mathrm{c}$ \\
& $\mathrm{Max}(\mathrm{mm})$ & 44.9 & 43.3 & 43.3 \\
& $\mathrm{Min}(\mathrm{mm})$ & 32.8 & 39.7 & 39.7 \\
& $\mathrm{SD}_{\mathrm{T}}(\mathrm{mm})$ & 3.1 & 1.0 & 1.0 \\
& $\mathrm{CV}_{\mathrm{T}}(\%)$ & 7.8 & 2.5 & 2.1
\end{tabular}

$\mathrm{SD}_{\mathrm{S}}$ of SWS is the standard deviation of the mean spatial SWS; $\mathrm{CV}_{\mathrm{S}}$ of SWS is the coefficient of variation of the mean spatial SWS. $\mathrm{SD}_{\mathrm{T}}$ refers to standard deviation of time series of the mean spatial SWS, $\mathrm{SD}_{\mathrm{S}}$ of the spatial SWS, and $\mathrm{CV}_{\mathrm{S}}$ of the spatial SWS; $\mathrm{CV}_{\mathrm{T}}$ refers to the coefficient of variation of time series of the mean spatial $\mathrm{SWS}, \mathrm{SD}_{\mathrm{S}}$ of the spatial $\mathrm{SWS}$, and $\mathrm{CV}_{\mathrm{S}}$ of the spatial SWS

*Values followed by the same letter are not significantly different at $P<0.05$

influenced by precipitation and plant activity in the 1.0-2.0and $2.0-3.0-\mathrm{m}$ layers than in the $0-1.0-\mathrm{m}$ layer. The changes in the mean SWS were mainly observed in the shallow soil layer $(0-1.0 \mathrm{~m})$, in agreement with the findings by Choi and Jacobs (2007), Hu et al. (2010a), Gao and Shao (2012b), and Jia et al. (2013a). Gao and Shao (2012b) found that the coefficient of variation of the mean SWS decreased over time from $20.7 \%$ for the $0-1.0-\mathrm{m}$ layer to $12.6 \%$ for the $1.0-3.0-\mathrm{m}$ layers.

The temporal changes in the standard deviation $\left(\mathrm{SD}_{\mathrm{S}}\right)$ and coefficient of variation $\left(\mathrm{CV}_{\mathrm{S}}\right)$ over space of the SWS for the various soil layers are shown in Fig. 3b, c. The time-averaged mean $\mathrm{SD}_{\mathrm{S}}$ and $\mathrm{CV}_{\mathrm{S}}$ were 58.6, 57.3, and $64.8 \mathrm{~mm}$, and 39.4, 41.4 , and $45.2 \%$ for the $0-1.0-, 1.0-2.0-$, and $2.0-3.0-\mathrm{m}$ soil layers, respectively (Table 2). Furthermore, the $\mathrm{SD}_{\mathrm{S}}$ and $\mathrm{CV}_{\mathrm{S}}$ were both significantly higher for the 2.0-3.0-m layer than for the $0-1.0-$ and $1.0-2.0-\mathrm{m}$ layers $(P<0.05)$ (Fig. $3 \mathrm{~b}, \mathrm{c}$ and Table 2). These results indicated that SWS in the deeper soil layers had relatively higher spatial variability compared to that in the shallower soil layers, consistent with other reports (Gao and Shao 2012b; Jia et al. 2013a). Two reasons may explain this result. First, the soil properties and root system controlling the SWS had relatively higher spatial variability in deeper layer. Second, precipitation recharge can weaken the effect 
of soil and plants on the soil moisture in shallow layer and thus decrease the difference of SWS over space.

The standard deviations $\left(\mathrm{SD}_{\mathrm{T}}\right)$ and coefficients of variation $\left(\mathrm{CV}_{\mathrm{T}}\right)$ over time of the mean SWS decreased from $22.2 \mathrm{~mm}$ and $14.9 \%$ in $0-1.0-\mathrm{m}$ layer to $6.6 \mathrm{~mm}$ and $4.6 \%$ in $2.0-3.0-\mathrm{m}$ layer, respectively (Table 2), indicating that temporal changes in the mean SWS decreased with increasing soil depth. Similar results were also observed by Choi and Jacobs (2007) and Gao and Shao (2012b). Moreover, the timeaveraged spatial variability of the mean SWS also decreased with increasing soil depth (Table 2). The $\mathrm{CV}_{\mathrm{T}}$ of the $\mathrm{SD}_{\mathrm{S}}$ and the $\mathrm{CV}_{\mathrm{S}}$ of SWS for the $0-1.0$ - and 2.0-3.0-m soil layers were 11.1 and $7.8 \%$ and 6.5 and $2.1 \%$, respectively, indicating that the mean SWS was more temporally stable in the deeper soil layers, in agreement with other findings (Lin 2006; Guber et al. 2008; Gao and Shao 2012a; Jia et al. 2013a).

\subsection{Temporal stability of SWS for the various soil layers}

The Spearman's rank correlation coefficient was used to investigate the overall temporal stability of the spatial patterns of SWS between different sampling occasions. The rank correlation matrix of the various sampling occasions is presented only for the $0-1.0-\mathrm{m}$ soil layer (Table 3 ). The relationships were all significant $(P<0.01)$ for each soil layer, indicating strong temporal stability in the spatial pattern of SWS. These results are consistent with the findings in other areas (Vachaud
Table 4 Statistical summary of the Spearman's rank correlation coefficients for the various soil layers

\begin{tabular}{llll}
\hline Parameter & $0-1.0 \mathrm{~m}$ & $1.0-2.0 \mathrm{~m}$ & $2.0-3.0 \mathrm{~m}$ \\
\hline Max & 0.997 & 0.998 & 0.999 \\
Min & 0.937 & 0.883 & 0.914 \\
Mean & $0.966 * \mathrm{a}$ & $0.961 \mathrm{a}$ & $0.979 \mathrm{~b}$ \\
SD & 0.015 & 0.028 & 0.020 \\
CV $(\%)$ & 1.561 & 2.941 & 2.079
\end{tabular}

*Values followed by the same letter are not significantly different at $P<0.05$ level

et al. 1985; Brocca et al. 2009; Heathman et al. 2009; Zhang and Shao 2013). The average rank correlation coefficients were $0.966,0.961$, and 0.979 for the $0-1.0-, 1.0-2.0-$, and 2.0-3.0-m soil layers, respectively (Table 4 ). The mean rank correlation coefficient was significantly higher $(P<0.01)$ in the $2.0-3.0-\mathrm{m}$ soil layer than in the $0-1.0-$ and $1.0-2.0-\mathrm{m}$ soil layers (Table 4), suggesting that the deep soil layer can retain a stronger temporally stable spatial pattern of SWS (Lin 2006; Guber et al. 2008; Gao and Shao 2012a).

Figure 4 shows the mean Spearman's rank correlation coefficients between sampling occasions with different time lags for the various soil layers. The mean rank correlation coefficient decreased with increasing time lags from 0.988 to 0.940 and from 0.994 to 0.950 for the $1.0-2.0-$ and $2.0-3.0-\mathrm{m}$ soil

Table 3 Matrix of Spearman's rank correlation coefficients corresponding to the measurements of soil water storage (SWS) at 135 locations on 18 dates for the $0-1.0-\mathrm{m}$ layer

\begin{tabular}{|c|c|c|c|c|c|c|c|c|c|c|c|c|c|c|c|c|c|}
\hline Date & $\mathrm{A} 2$ & A3 & A4 & A5 & A6 & A7 & A8 & A9 & A 10 & A11 & A12 & A13 & A14 & A15 & A16 & A17 & A 18 \\
\hline $\mathrm{A} 1$ & 1.00 & 0.99 & 0.99 & 0.99 & 0.99 & 0.98 & 0.97 & 0.96 & 0.96 & 0.96 & 0.96 & 0.97 & 0.97 & 0.97 & 0.96 & 0.97 & 0.97 \\
\hline $\mathrm{A} 2$ & 1.00 & 1.00 & 1.00 & 0.99 & 0.99 & 0.98 & 0.97 & 0.96 & 0.95 & 0.96 & 0.97 & 0.97 & 0.97 & 0.97 & 0.96 & 0.96 & 0.96 \\
\hline $\mathrm{A} 3$ & & 1.00 & 1.00 & 0.99 & 0.99 & 0.98 & 0.96 & 0.95 & 0.95 & 0.96 & 0.96 & 0.97 & 0.97 & 0.97 & 0.95 & 0.96 & 0.96 \\
\hline A4 & & & 1.00 & 0.99 & 0.99 & 0.98 & 0.97 & 0.95 & 0.95 & 0.96 & 0.96 & 0.97 & 0.97 & 0.97 & 0.96 & 0.96 & 0.96 \\
\hline A5 & & & & 1.00 & 1.00 & 0.99 & 0.98 & 0.96 & 0.96 & 0.96 & 0.96 & 0.96 & 0.97 & 0.97 & 0.96 & 0.96 & 0.96 \\
\hline A6 & & & & & 1.00 & 0.99 & 0.97 & 0.96 & 0.95 & 0.95 & 0.95 & 0.96 & 0.96 & 0.96 & 0.96 & 0.96 & 0.96 \\
\hline A7 & & & & & & 1.00 & 0.99 & 0.98 & 0.97 & 0.96 & 0.95 & 0.95 & 0.96 & 0.96 & 0.95 & 0.96 & 0.96 \\
\hline A8 & & & & & & & 1.00 & 0.99 & 0.98 & 0.96 & 0.95 & 0.95 & 0.96 & 0.96 & 0.96 & 0.96 & 0.96 \\
\hline A9 & & & & & & & & 1.00 & 0.98 & 0.97 & 0.94 & 0.95 & 0.95 & 0.95 & 0.95 & 0.95 & 0.95 \\
\hline A 10 & & & & & & & & & 1.00 & 0.98 & 0.96 & 0.96 & 0.96 & 0.96 & 0.95 & 0.95 & 0.95 \\
\hline A11 & & & & & & & & & & 1.00 & 0.98 & 0.97 & 0.98 & 0.97 & 0.94 & 0.94 & 0.94 \\
\hline A 12 & & & & & & & & & & & 1.00 & 0.99 & 0.99 & 0.99 & 0.95 & 0.95 & 0.95 \\
\hline A13 & & & & & & & & & & & & 1.00 & 1.00 & 0.99 & 0.95 & 0.95 & 0.95 \\
\hline A14 & & & & & & & & & & & & & 1.00 & 1.00 & 0.95 & 0.96 & 0.95 \\
\hline A15 & & & & & & & & & & & & & & 1.00 & 0.95 & 0.95 & 0.95 \\
\hline A16 & & & & & & & & & & & & & & & 1.00 & 0.99 & 0.99 \\
\hline A 17 & & & & & & & & & & & & & & & & 1.00 & 1.00 \\
\hline
\end{tabular}

All comparisons were significant at $P<0.001$ level. The capital letter A refers to the soil layer of $0-1.0 \mathrm{~m}$. The numbers of 1 to 18 refer to the measurement dates-Dec 16 in 2012, and Jan 21, Feb 24, Mar 18, Apr 16, May 1, May16, May 31, Jun 15, Jun 30, Jul 15, Jul 30, Aug 14, Aug 29, Sept 13, Sept 28, Oct 13, and Oct 28 in 2013, respectively 
Fig. 4 Mean Spearman's rank correlation coefficients corresponding to different time lags for the various soil layers

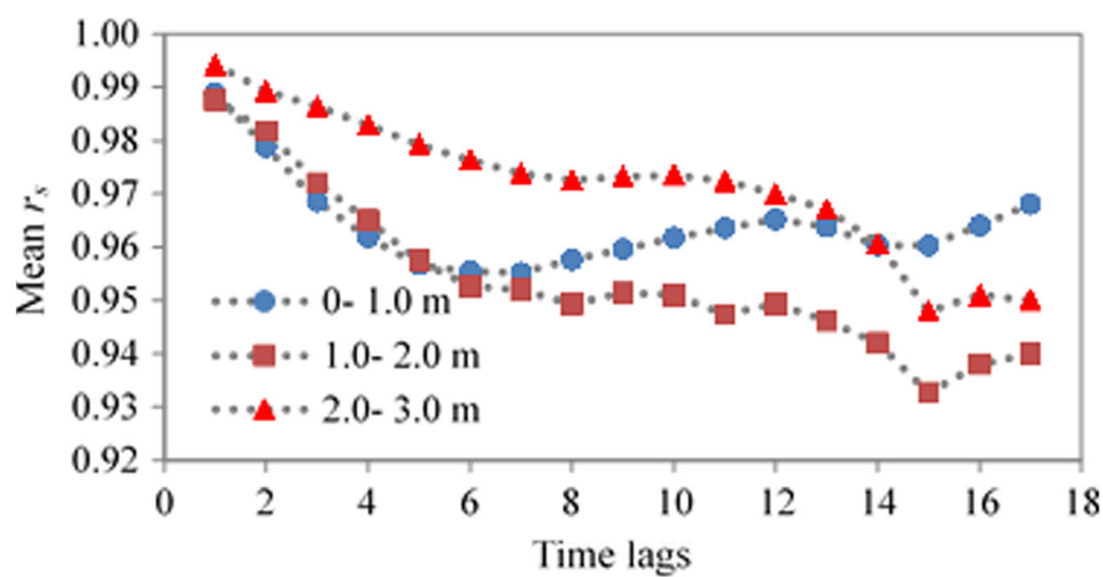

layers, respectively (Fig. 4). Similar results have been reported by other studies (Schneider et al. 2008; Biswas and Si 2011a; Penna et al. 2013; Zhang and Shao 2013). For example, Biswas and Si (2011a) showed that the rank coefficient gradually decreased with increasing intervals between soil layers during both the discharge and recharge periods in a hummocky landscape in Canada. Zhang and Shao (2013) observed that soil surface water content in a desert area had higher correlations between water series sampled over short periods of time and decreased with increasing time lags. The
Fig. 5 Ranked mean relative differences with their standard deviations for soil water storage (SWS) and the index of temporal stability (ITS) of each sampling location for the various soil layers. Vertical bars indicate \pm 1 standard deviation of relative difference. The bold curve indicates the ITS, and the representative locations with ITSs under $10 \%$ are marked in red. $N R L$ indicates the site number of the representative locations

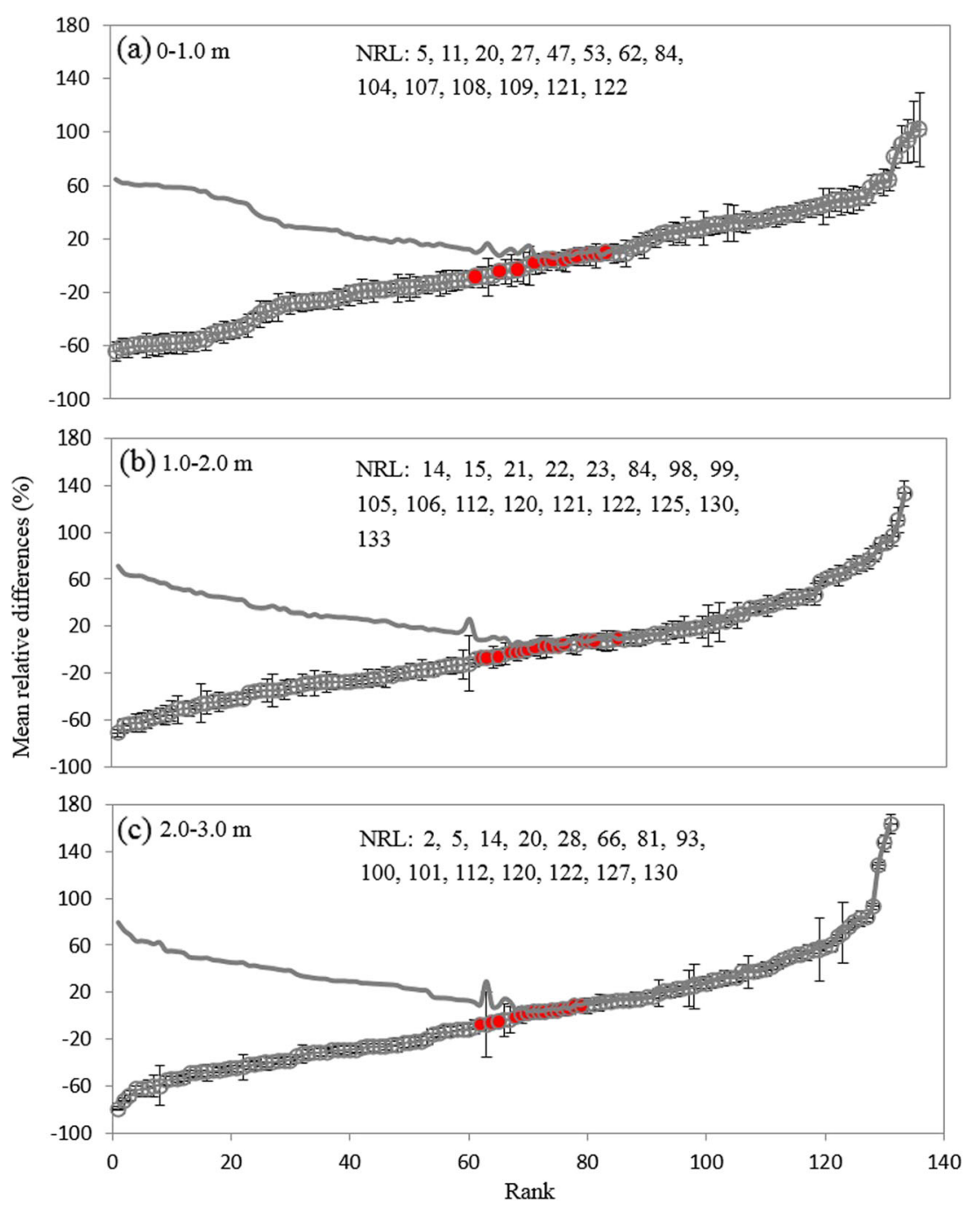


mean rank correlation coefficient, however, decreased from 1 to 7 time lags and then fluctuated from 8 to 17 time lags for the $0-1.0-\mathrm{m}$ soil layer. These results may be attributed to rainfall infiltration and consumption of water by plants, which can disturb the hydrological process in shallow layers more than in deeper layers (Choi and Jacobs 2007; Gao and Shao 2012b; Penna et al. 2013). First of all, much of the precipitation can generally infiltrate to a depth of approximately $1 \mathrm{~m}$ due to less rainfall in this semi-arid area (Gao and Shao 2012a). Moreover, plants generally absorb water mainly from shallow soil (Feddes et al. 1978; Morris 2006) because most roots concentrate in 0-1.0-m layer (Jia et al. 2011; Cheng et al. 2013) and thus mainly affect the dynamics of soil water in the $0-1.0-\mathrm{m}$ soil layer.

Figure 5 shows the ranked MRD in SWS, the associated SDRD, and the ITS of each sampling location for the various soil depths. The ranges of the MRD were 166.0, 204.3, and $242.3 \%$ for the 0-1.0-, 1.0-2.0-, and 2.0-3.0-m soil layers, respectively (Table 5 ). The increasingly wider ranges of the MRD from the 0-1.0-m to the 2.0-3.0-m layer may be ascribed to the higher spatial variability of SWS in deeper soil layers (Table 2 and Fig. 3). The increasing ranges of the MRD with increasing soil depth were consistent with other findings

Table 5 Statistical summary of the mean relative difference (MRD) and its associated standard deviation (SDRD) and mean absolute bias error (MABE) of soil water storage (SWS) for the various soil layers

\begin{tabular}{llll}
\hline Parameters & $0-1.0 \mathrm{~m}$ & $1.0-2.0 \mathrm{~m}$ & $2.0-3.0 \mathrm{~m}$ \\
\hline MRD (\%) & & & \\
Max & 101.7 & 133.2 & 163.3 \\
Min & -64.3 & -71.1 & -79.0 \\
Range & 166.0 & 204.3 & 242.3 \\
$\mathrm{~N}_{1}$ & 13 & 13 & 12 \\
SDRD (\%) & & & \\
Mean & $7.6 * \mathrm{a}$ & $6.7 \mathrm{~b}$ & $5.4 \mathrm{c}$ \\
Max & 27.4 & 23.5 & 28.0 \\
Min & 2.5 & 2.5 & 1.5 \\
Range & 24.9 & 21.0 & 26.6 \\
$\mathrm{~N}_{2}$ & 15 & 44 & 86 \\
MABE (\%) & & & \\
Mean & $6.8 \mathrm{a}$ & $6.2 \mathrm{a}$ & $4.7 \mathrm{~b}$ \\
Max & 16.6 & 25.4 & 29.1 \\
Min & 1.5 & 1.7 & 0.7 \\
Range & 15.1 & 23.7 & 28.4 \\
$\mathrm{~N}_{3}$ & 46 & 73 & 104 \\
\hline
\end{tabular}

$\mathrm{N}_{1}$ indicates the number of locations with mean relative difference ranging from -5 to $5 \%, \mathrm{~N}_{2}$ the number of locations with standard deviation of relative difference $<5 \%$, and $\mathrm{N}_{3}$ the number of locations with mean absolute bias error $<5 \%$

*Values followed by the same letter are not significantly different at $P<0.05$ in the same area (Gao and Shao 2012b; Jia et al. 2013a). Similarly, Brocca et al. (2009) found that the range of the MRD increased with sampling scale due to the larger variations in soil, vegetation, and terrain at larger scales. The number of locations with the MRD ranging from -5 to $5 \%$ was 13 , 13 , and 12 for the $0-1.0-, 1.0-2.0-$, and $2.0-3.0-\mathrm{m}$ soil layers, respectively (Table 5), indicating that the number of locations with an MRD of $\pm 5 \%$ were less dependent on soil depth.

The mean SDRDs decreased with increasing soil depth from $7.6 \%$ for the $0-1.0-\mathrm{m}$ layer to $5.4 \%$ for the $2.0-3.0-\mathrm{m}$ layer, and the mean MABEs decreased similarly from 6.8 to $4.7 \%$. Locations with an SDRD and/or MABE $<5 \%$ are considered to be temporally stable (Starks et al. 2006; Hu et al. 2010b). The number of temporally stable locations thus generally increased with increasing soil depth, according to both the SDRD and MABE. For example, the number of locations with an SDRD or MABE $<5 \%$ was 15 or 46 for the $0-1.0-\mathrm{m}$ layer, respectively, and the $2.0-3.0-\mathrm{m}$ layer had 86 or 104 temporally stable locations, respectively (Table 5). The SWS in the deep layer thus tended to be more temporally stable, consistent with the results of the Spearman's rank correlation analysis. Our results agreed with the findings of other studies in the same area (Gao and Shao 2012b; She et al. 2014). The SWS with the higher temporal stability in the deep layer was probably due to the reduced dependence on the climatic, vegetational, and hydrological factors that can affect the dynamics of soil moisture (Pachepsky et al. 2005; Vanderlinden et al. 2012). The MABE identified more temporally stable locations than the SDRD index for each soil layer (Table 5).

The representative sites can be selected from temporally stable locations with ITS under $10 \%$, for directly estimating the mean SWS for the various soil layers of the transect. We identified 14, 17, and 15 representative locations for the 0 $1.0-, 1.0-2.0-$, and $2.0-3.0-\mathrm{m}$ soil depths, respectively (Fig. 5). Eight locations (5, 14, 20, 84, 112, 120, 121, and 130) were simultaneously representative for two soil depths for mean SWS estimation (Fig. 5). Only one location (122) could simultaneously represent all three soil layers for estimating SWS. Some studies have reported that locations able to represent mean SWS for all soil layers were difficult to find (Vanderlinden et al. 2012); Hu et al. (2010b) found zero representative location of 128 sampling locations for four soil layers. Finding one location to represent the mean SWS of the landscape-scale transect for the various soil layers can reduce labor and costs, but the accuracy of prediction may not be the best among all representative locations. According to the RMSE, the representative locations with the best accuracy of prediction for the 0-1.0-, 1.0-2.0-, and 2.0-3.0-m soil layers were 107, 21, and 127, respectively. Linear fitting between the transect mean SWS and the SWS of the best representative location for the soil layers are shown in Fig. 6. The RMSEs were $8.75,5.93$, and 4.97 for the $0-1.0-, 1.0-2.0-$, and 2.0 
Fig. 6 Linear fitting between the transect mean SWS and the SWSs of the best representative locations for the various soil layers (locations 107, 21, and 127 for the $0-1.0-, 1.0-2.0-$, and 2.0 $3.0-\mathrm{m}$ soil layers, respectively)

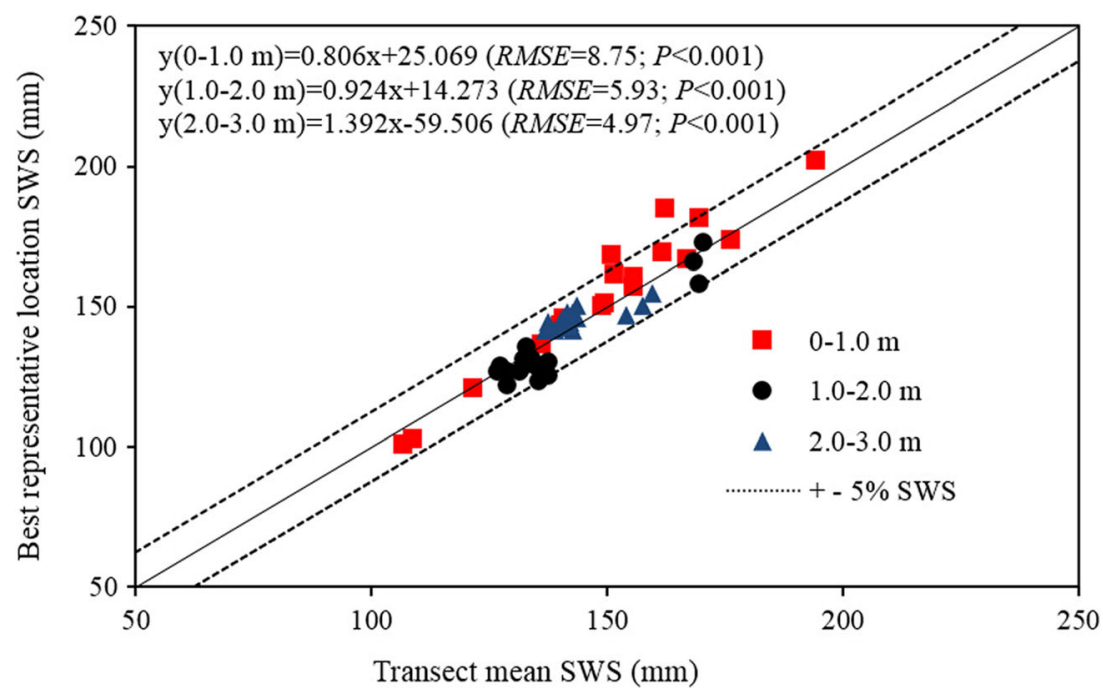

3.0-m soil layers, respectively, indicating that the accuracy of prediction increased with increasing soil depth. The selected representative locations could directly estimate the mean SWSs well $(P<0.001)$, which can reduce time, labor, and other costs for measuring and predicting soil moisture.

Field experiments in the same study area have been conducted to examine the temporal stability of soil moisture at various spatial scales, such as plot (Gao et al. 2011; Jia and Shao 2013; Jia et al. 2013b), slope (Jia et al. 2013a), and watershed (Hu et al. 2010b) scales. Our study found similar trends of the MRD and SDRD of SWS at the landscape scale. However, the predictive functions for the various soil layers at the landscape scale may be used to estimate the mean SWS of the entire catchment compared to the plot and slope scales, because the landscape scale can be more representative of the soil texture, terrain, and vegetation for the entire catchment.

\subsection{Factors controlling the temporal stability of SWS}

Many factors have been reported to have an effect on the temporal stability of the spatial pattern of soil moisture (Gómez-Plaza et al. 2001; da Silva et al. 2001; Mohanty and Skaggs 2001; Jacobs et al. 2004; Cosh et al. 2008; Zhao et al. 2010). To examine whether the temporal stability of SWS depends on soil, topographical, and vegetational properties, we used Pearson correlation to determine the relationships between the MRD and selected properties (Table 6). The MRD was positively correlated with clay, silt, and OC contents but negatively correlated with bulk density, saturated soil hydraulic conductivity, and sand content (Table 6), in agreement with the findings by Zhang and Shao (2013). It was well known that soil properties play important roles in controlling the temporal stability of SWS, as did Cosh et al. (2008) and Hu et al. (2010b), Cosh et al. (2008) identified bulk density as the most important parameter affecting the MRD, accounting for $32 \%$ of its variability. Hu et al. (2010b) found that soil texture could significantly affect the temporal stability of the soil water content. Soil OC content was positively correlated with the MRD, in agreement with the findings by Zhao et al. (2010), Biswas and Si (2011b), and Jia et al. (2013a). Soil OC content can significantly improve soil structure and thus affect the spatiotemporal patterns of soil water content (Wang et al. 2013).

The MRD was not obviously correlated with site elevation, except for the 2.0-3.0-m layer (Table 6). In contrast, Jia et al. (2013a) reported that the MRD was highly dependent on site elevation for various soil layers on a hillslope. Wang et al. (2013) indicated that site elevation had a pronounced inverse relationship with the MRD for various soil layers in an artificially revegetated desert area. Biswas and Si (2011b) further
Table 6 Pearson correlation matrix between the MRD and selected properties of the soil (bulk density, BD; saturated soil hydraulic conductivity, Ks; clay content, Clay; silt content, Silt; sand content,
Sand; and organic-carbon content, OC), topography (site elevation, SE), and vegetation (aboveground biomass, AGB)

\begin{tabular}{llllllrr}
\hline Depth & BD & Ks & Clay & Silt & Sand & OC & SE \\
\hline $0-1.0 \mathrm{~m}$ & $-0.59^{* *}$ & $-0.53^{* *}$ & $0.62^{* *}$ & $0.64^{* *}$ & $-0.65^{* *}$ & $0.35^{* *}$ & 0.04 \\
$1.0-2.0 \mathrm{~m}$ & $-0.40^{* *}$ & $-0.34^{* *}$ & $0.45^{* *}$ & $0.43^{* *}$ & $-0.44^{* *}$ & $0.22^{*}$ & -0.09 \\
$2.0-3.0 \mathrm{~m}$ & $-0.21^{*}$ & $-0.20^{*}$ & $0.27^{* *}$ & $0.23^{* *}$ & $-0.24^{* *}$ & 0.05 & $-0.21^{*}$ \\
\hline
\end{tabular}

*Correlation is significant at the 0.05 level (two-tailed); **correlation is significant at the 0.01 level (two-tailed) 
indicated that the correlation between SWS and elevation was reasonably persistent at a large scale. In our study, the relationship between elevation and soil water content was not consistent. The weak correlations between the MRD and site elevation in the $0-1.0$ - and $1.0-2.0-\mathrm{m}$ soil layers may be attributed to the heterogeneity of the plants. An uneven distribution of plant cover and roots can affect the redistribution of soil water and can complicate this correlation (Gómez-Plaza et al. 2000; Cantón et al. 2004; Zhao et al. 2010). For example, Gómez-Plaza et al. (2000) showed that variation in plant cover decreased the temporal stability of soil water and masked the effect of topography. In addition, some species with higher levels of evapotranspiration (e.g., alfalfa) may also affect the redistribution of soil water (Jia et al. 2013b). Variations in the vegetation can thus weaken the effect of topography on the temporal stability of SWS, especially in shallow soil. The MRD was nevertheless significantly correlated with site elevation in the 2.0-3.0-m layer, in agreement with other studies (Jia et al. 2013a; Lin 2006). We attributed this obvious topographical effect on SWS in the deep layer to the diverse terrains (Grayson et al. 2002; Lin 2006) in this area. The redistribution of sub-surface water in deeper layers during a few short periods can be dominated by the more common vertical fluxes in semiarid areas (Zhao et al. 2010). We also observed a weak correlation between the MRD and aboveground biomass (Table 6), which was inconsistent with other findings (Hupet and Vanclooster 2002; Jia et al. 2013a), perhaps because correlations derived from a single measurement of aboveground biomass would not capture seasonal variations (Zhao et al. 2010). In comparison with landscape scale of this study, Jia and Shao (2013) reported that plant type and aboveground biomass were the main factors affecting temporal stability of SWS at plot scale, and Jia et al. (2013a) found that elevation, litter fall, and aboveground biomass significantly correlated with temporal stability at slope scale, indicating that the effects of factors on the temporal stability of SWS were scale dependent. This can be ascribed to that different factors and processes that may operate at different scales and/or at different intensities (Hu et al. 2014).

All the above results generally indicated that soil, topographical, and vegetational properties affected the temporal stability of SWS; the predominant controlling factors, however, varied with study area due to different scales, climatic conditions, and other factors.

\section{Conclusions}

The temporal stability of SWS was investigated in 0-1.0-, 1.0-2.0-, and 2.0-3.0-m soil layers at the landscape scale at 135 locations on 18 measurement occasions in a typical transect in a semiarid catchment on the Loess Plateau. Temporal changes in the mean SWS were mainly observed in the shallow layer $(0-1.0 \mathrm{~m})$, while the mean SWS in the deep soil layer $(2.0-3.0 \mathrm{~m})$ had relatively greater spatial variation. Temporal-spatial variations of SWS were depth dependent. Spearman's rank correlation coefficients were significant $(P<0.05)$ between any two measurement occasions and increased with increasing soil depth. The rank correlation coefficients decreased with increasing time lags for the 1.0-2.0and $2.0-3.0-\mathrm{m}$ soil layers, but the trend of correlation coefficients for the $0-1.0-\mathrm{m}$ layer first decreased and then fluctuated with increasing time lags. The number of temporally stable locations, as identified by the SDRD and MABE, increased with increasing soil depth, indicating that SWS was more temporally stable in deeper soil layers. The representative site with best accuracy of prediction for each soil layer based on the RMSE could estimate the mean SWSs well. The highest accuracy of prediction increased with increasing soil depth. Soil texture, OC content, bulk density, and saturated soil hydraulic conductivity significantly affected the temporal stability of SWS for the various layers, while aboveground biomass and site elevation (except for the 2.0-3.0-m layer) had a weak effect on the temporal stability of SWS at the landscape scale.

Acknowledgments This study was financially supported by the National Natural Science Foundation of China (No. 51179180 and 41390463). Dr. Zhao CL is acknowledged for his zealous help in the field data collection.

\section{References}

Biswas A, Si BC (2011a) Depth persistence of the spatial pattern of soil water storage in a hummocky landscape. Soil Sci Soc Am J 75: 1099-1109

Biswas A, Si BC (2011b) Identifying scale specific controls of soil water storage in a hummocky landscape using wavelet coherency. Geoderma 165:50-59

Brocca L, Melone F, Moramarco T, Morbidelli R (2009) Soil moisture temporal stability over experimental areas in Central Italy. Geoderma 148:364-374

Brocca L, Tullo T, Melone F, Moramarco T, Morbdelli R (2012) Catchment scale soil moisture spatial-temporal variability. J Hydrol 422:63-75

Cantón Y, Solé-Benet A, Domingo F (2004) Temporal and spatial patterns of soil moisture in semiarid badlands of SE Spain. J Hydrol 285:199-214

Cheng XR, Huang MB, Si BC, Yu MK, Shao MA (2013) The differences of water balance components of Caragana korshinkii grown in homogeneous and layered soils in the desert-Loess Plateau transition zone. J Arid Environ 98:10-19

Choi M, Jacobs JM (2007) Soil moisture variability of root zone profiles within SMEX02 remote sensing footprints. Adv Water Resour 30: 883-896

Cosh MH, Jackson TJ, Moran S, Bindlish R (2008) Temporal persistence and stability of surface soil moisture in a semi-arid watershed. Remote Sens Environ 112:304-313 
da Silva AP, Nadler A, Kay BD (2001) Factors contributing to temporal stability in spatial patterns of water content in the tillage zone. Soil Tillage Res 58:207-218

Dumedah G, Coulibaly P (2011) Evaluation of statistical methods for infilling missing values in high-resolution soil moisture data. J Hydrol 400:95-102

Famiglietti JS, Rudnicki JW, Rodell M (1998) Variability in surface moisture content along a hillslope transect: rattlesnake hill, Texas. J Hydrol 210:259-281

Feddes RA, Kowalik PJ, Zaradny H (1978) Simulation of field water use and crop yield. Halsted, New York

Gao L, Shao MA (2012a) Temporal stability of shallow soil water content for three adjacent transects on a hillslope. Agric Water Manag 110: $41-54$

Gao L, Shao MA (2012b) Temporal stability of soil water storage in diverse soil layers. Catena 95:24-32

Gao XD, Wu PT, Zhao XN, Shi YG, Wang JW (2011) Estimating spatial mean soil water contents of sloping jujube orchards using temporal stability. Agric Water Manag 102:66-73

Gómez-Plaza A, Alvarez-Rogel J, Albaladejo J, Castillo VM (2000) Spatial patterns and temporal stability of soil moisture across a range of scales in a semi-arid environment. Hydrol Process 14:1261-1277

Gómez-Plaza A, Martínez-Mena M, Albaladejo J, Castillo VM (2001) Factors regulating spatial distribution of soil water content in small semiarid catchments. J Hydrol 253:211-226

Grayson RB, Blöschl G, Western AW, McMahon TA (2002) Advances in the use of observed spatial patterns of catchment hydrological response. Adv Water Resour 25:1313-1334

Grayson RB, Western AW (1998) Towards areal estimation of soil water content from point measurements: time and space stability of mean response. J Hydrol 207:68-82

Guber AK, Gish TJ, Pachepsky YA, van Genuchten MT, Daughtry CST, Nicholson TJ, Cady RE (2008) Temporal stability in soil water content patterns across agricultural fields. Catena 73:125-133

Heathman GC, Cosh MH, Merwade V, Han E (2012) Multi-scale temporal stability analysis of surface and subsurface soil moisture within the Upper Cedar Creek Watershed, Indiana. Catena 95:91-103

Heathman GC, Larose M, Cosh MH, Bindlish R (2009) Surface and profile soil moisture spatio-temporal analysis during an excessive rainfall period in the Southern Great Plains, USA. Catena 78:159-169

Hu W, Biswas A, Si BC (2014) Application of multivariate empirical mode decomposition for revealing scale-and season-specific time stability of soil water storage. Catena 113:377-385

$\mathrm{Hu}$ W, Shao MA, Reichardt K (2010a) Using a new criterion to identify sites for mean soil water storage evaluation. Soil Sci Soc Am J 74: 762-773

Hu W, Shao MA, Wang QJ, Reichardt K, Tan J (2010b) Watershed scale temporal stability of soil water content. Geoderma 158:181-198

$\mathrm{Hu}$ W, Si BC (2014) Can measurements of a certain depth be used to upscale soil water content of a soil profile at point or slope scale? J Hydrol 516:67-75

$\mathrm{Hu}$ W, Tallon LK, Si BC (2012) Evaluation of time stability indices for soil water storage upscaling. J Hydrol 475:2229-2241

Hupet F, Vanclooster M (2002) Intraseasonal dynamics of soil moisture variability within a small agricultural maize cropped field. J Hydrol 261:86-101

Jacobs JM, Mohanty BP, Hsu EC, Miller D (2004) SME02: field scale variability, time stability and similarity of soil moisture. Remote Sens Environ 92:436-446

Jia XX, Shao MA, Wei XR, Horton R, Li XZ (2011) Estimating total not primary productivity of managed grasslands by a state-space modeling approach in a small catchment on the Loess Plateau, China. Geoderma 160:281-291
Jia XX, Shao MA, Wei XR, Wang YQ (2013a) Hillslope scale temporal stability of soil water storage in diverse soil layers. J Hydrol 498: 254-264

Jia YH, Shao MA (2013) Temporal stability of soil water storage under four types of revegetation on the northern Loess Plateau of China. Agric Water Manag 117:33-42

Jia YH, Shao MA, Jia XX (2013b) Spatial pattern of soil moisture and its temporal stability within profiles on a loessial slope in northwestern China. J Hydrol 495:150-161

Kachanoski RG, de Jong E (1988) Scale dependence and the temporal stability of spatial patterns of soil water storage. Water Resour Res 24:85-91

Klute A, Dirksen C (1986) Hydraulic conductivity of saturated soils. In: Klute A (ed) Methods of Soil Analysis. ASA and SSSA, Madison, pp 694-700

Lin H (2006) Temporal stability of soil moisture spatial pattern and subsurface preferential flow pathways in the shale hills catchment. Vadose Zone J 5:317-340

Martínez-Fernández J, Ceballos A (2003) Temporal stability of soil moisture in a large-field experiment in Spain. Soil Sci Soc Am J 67: $1647-1656$

Maule CP, Chanasyk DS, Muehlenbachs K (1994) Isotopic determination of snow-water contribution to snow water and groundwater. J Hydrol 155:73-91

Mohanty BP, Skaggs TH (2001) Spatio-temporal evolution and timestable characteristics of soil moisture within remote sensing footprints with varying soil, slope, and vegetation. Adv Water Resour 24:1051-1067

Morris M (2006) Soil moisture monitoring: low cost tools and methods. Publication number IP277. Available online at http://attra.ncat.org/ attra-pub/soil moisture.html (verified 13 Apr. 2011). ATTRANational Sustainable Agriculture Information Service, Butte, MT

Nelson DW, Sommers LE (1982) Total carbon, organic carbon and organic matter. In: Page AL, Miller RH, Keeney DR (eds) Methods of Soil Analysis. Part 2. Agronomy Monograph, second ed. ASA and SSSA, Madison, pp 534-580

Pachepsky YA, Guber A, Jacques D (2005) Temporal persistence in vertical distribution of soil moisture contents. Soil Sci Soc Am J 69: 347-352

Penna D, Brocca L, Borga M, Dalla Fontana G (2013) Soil moisture temporal stability at different depths on two alpine hillslopes during wet and dry periods. J Hydrol 477:55-71

Schneider K, Huisman JA, Breuer L, Zhao Y, Frede HG (2008) Temporal stability of soil moisture in various semi-arid steppe ecosystems and its application in remote sensing. J Hydrol 359:16-29

She DL, Liu DD, Liu YY, Liu Y, Xu CL, Qu X, Chen F (2014) Profile characteristics of temporal stability of soil water storage in two land uses. Arab J Geosci 7:21-34

Starks PJ, Heathman GC, Jackson TJ, Cosh MH (2006) Temporal stability of soil moisture profile. J Hydrol 324:400-411

Vachaud G, Passerat de Silans A, Balabanis P, Vauclin M (1985) Temporal stability of spatially measured soil water probability density function. Soil Sci Soc Am J 49:822-828

Vanderlinden K, Vereecken H, Hardelauf H, Herbst M, Martínez G, Cosh MH, Pachepsky YA (2012) Temporal stability of soil water contents: a review of data and analyses. Vadose Zone J 11(4):1-19

Vivoni ER, Gebremichael M, Watts CJ, Bindlish R, Jackson TJ (2008) Comparison of ground-based and remotely-sensed surface soil moisture estimates over complex terrain during SMEX04. Remote Sens Environ 112:314-325

Wang XP, Pan YX, Zhang YF, Dou DQ, Hu R, Zhang H (2013) Temporal stability analysis of surface and subsurface soil moisture for a transect in artificial revegetation desert area, China. J Hydrol 507:100-109

Zhang PP, Shao MA (2013) Temporal stability of surface soil moisture in a desert area of northwestern China. J Hydrol 505:91-101 
Zhao Y, Peth S, Wang XY, Lin H, Horn R (2010) Controls of surface soil moisture spatial patterns and their temporal stability in a semi-arid steppe. Hydrol Process 24:2507-2519
Zhou X, Lin H, Zhu Q (2007) Temporal stability of soil moisture spatial variability at two scales and its implication for optimal field monitoring. Hydrol Earth Syst Sci Discuss 4:1185-1214 